\title{
Enhancing Rural Population Health Care Access and Outcomes Through the Telehealth EcoSystem ${ }^{\mathrm{TM}}$ Model
}

\author{
Brenda A. Leath ${ }^{1 *}$, Lucenia W. Dunn ${ }^{2}$, Antwon Alsobrook ${ }^{3}$, Madeline L. Darden $^{4}$ \\ 1. Westat, Rockville, MD \\ 2. Tuskegee Macon County Community Foundation, Inc., Tuskegee, AL \\ 3. A2D, Inc., Atlanta, GA \\ 4. Health Marketing Concepts International, Alexandria, VA
}

\begin{abstract}
The article highlights the Telehealth EcoSystem ${ }^{\mathrm{TM}}$ model, a holistic cross-sector approach for socioeconomic revitalization, connectivity, interoperability and technology infrastructure development to address health equity for rural underserved communities. Two guiding frameworks, Community \& Economic Development (CED) and Collective Impact, provided the foundation for the Telehealth EcoSystem $^{\mathrm{TM}}$ model. Public and private organizational capacities are addressed by comprehensive healthcare and social service delivery through stakeholder engagement and collaborative decision-making processes. A focus is maintained on economic recovery and policy reforms that enhance population health outcomes for individuals and families who have economic challenges.

The Telehealth EcoSystem ${ }^{\mathrm{TM}}$ utilizes an intranet mechanism that enables a range of technologies and electronic devices for health informatics and telemedicine initiatives. The relevance of the intranet to the advancement of health informatics is highlighted. Best practices in digital connectivity, HIPAA requirements, electronic health records (EHRs), and eHealth applications, such as patient portals and mobile devices, are emphasized. Collateral considerations include technology applications that expand public health services.

The ongoing collaboration between a social science research corporation, a regional community foundation and an open access telecommunications carrier is a pivotal element in the sequential development and implementation of the Telehealth EcoSystem ${ }^{\mathrm{TM}}$ model in the rural southeastern region community.
\end{abstract}

Keywords: Community and economic development; collective impact; telehealth; care coordination; research; intranet

Abbreviations: HIPAA (Health Insurance Portability and Accountability Act), EHRs (electronic health records), TMCCF (Tuskegee Macon County Community Foundation), CED (Community \& Economic Development)

*Correspondence: Brenda Leath, email: leathbrenda2@gmail.com

DOI: 10.5210/ojphi.v10i2.9311

Online Journal of Public Health Informatics * ISSN 1947-2579* http://ojphi.org * 10(2):e218, 2018 
Copyright @2018 the author(s)

This is an Open Access article. Authors own copyright of their articles appearing in the Online Journal of Public Health Informatics. Readers may copy articles without permission of the copyright owner(s), as long as the author and OJPHI are acknowledged in the copy and the copy is used for educational, not-for-profit purposes.

\section{Introduction}

Health equity is an essential element in the global quest for social justice, human rights and environmental sustainability [1]. Unfortunately, rural communities in the United States are often disproportionately impacted by socioeconomic conditions and health disparities. Approximately one-fifth of the U.S. population resides in rural America, and health care providers encounter a patient base that is generally older, sicker, and less affluent than their urban counterparts [2-4]. According to a recent Rural Healthy People 2020 report, "Rural health challenges are complex, reflecting both significant disparities across rural populations residing in the United States and unique regional, political and social differences." [5] The former Director of the U.S. Office of Rural Health Policy asserts that the country "lacks strong infrastructure in rural population health" and that "rural demography [can] seem as complex and locale-specific as fingerprints." [5] Community mobilization geared toward local and region-centric innovations and solutions is an optimal approach to addressing the variability in rural health care issues. "Understanding these differences is critical to taking steps to improve health and well-being in rural areas and to reduce health disparities among rural populations.” [3]

Macon County, Alabama, is one of several counties in Alabama’s Black Belt Region [6] that are rich in historical events and legacies-particularly regarding African American communitiesalong with the topography and natural resources. Located in a southern rural region, the city of Tuskegee and Macon County, Alabama (AL) continue to endure intractable socioeconomic hardships despite a rich and storied history of academic, entrepreneurial, cultural and scientific achievements. Economic distress is prevalent in multiple arenas including housing, commerce, unemployment, telecommunications, transportation infrastructure and health care access $[7,8]$. Wide-scale disparities prevail as a result of a decades-long population exodus; diminishing financial and environmental infrastructure; and limited resources to address community needs.

The "Black Belt" designation originally referenced the rich soil and verdant landscape that drew whites as landowners to the area and who built large plantations with an emphasis on growing cotton and other agricultural products. The regional descriptor evolved to later encompass the large concentration of African American residents who were slaves on those plantations and, upon emancipation, were left with an impoverished status that continues to this day $9,10,11$ This phenomenon is encapsulated in a Journal of Southern Space article that describes the "historicalgeographical Black Belt, beginning as a rich, dark-soil, cotton-growing region of Alabama occupied by slaveholders in the 1820s and 30s, and becoming, over time, a more generalized designation for a region or place with a majority black population. By the late twentieth century, the Alabama Black Belt, as a region of insurgent African American aspirations, made a strong claim to take over the meaning of the term from its older and other senses.” [9] 


\section{Catchment Area Demographics}

Macon County, Alabama, is situated in the east-central portion of the state and bordered by Elmore, Tallapoosa, Lee, Russell, Bullock, and Montgomery counties. Macon's county seat is located in the city of Tuskegee, AL. Geographically, Macon County consists of 611 square miles comprising $1.2 \%$ of the total land area in the state. According to the U.S. Census Bureau, total population estimates for Macon County are said to be approximately 18,963 [10]. Demographic indices reflect the population composition as follows: $16.4 \%$ whites, $81.4 \%$ Black/African Americans, 0.3\% American Indian, $0.5 \%$ Asian, $1.5 \%$ person with two or more races, $1.5 \%$ Hispanic or Latino, and 15.6\% White alone, not Hispanic.

\section{Historical Perspective}

Conditions in the historic Black Belt remain some of the worst in the United States [11]. Current indices clearly highlight significant cumulative demographic and economic changes that are indicative of disparities and marked distress factors. The Robert Wood Johnson Foundation's (RWJF's) [12] recent jurisdictional comparative study ranked Macon County $62^{\text {nd }}$ of 67 Alabama counties in terms of population health outcome factors, predicated on weighted scores for health behaviors, clinical care, social, and economic data. Macon County was also ranked 54 ${ }^{\text {th }}$ out of 67 counties comparatively in the category of overall health factors in this RWJF report. The region also suffered historical declines in national and local agriculture/agri-business-including traditional and non-conventional farming, forestry, livestock commerce, and the export trade markets. Market deficits related to the agricultural industry in Macon County have impacted the African American and population in particular [13].

Rural inequities such as these are an excellent example of the intersectionality of the factors that contribute to disparities [3]. The use of history and culture can be tremendous assets for rural communities and can be leveraged to improve health outcomes [3]. As noted earlier, Macon County enjoys a storied history of cultural, intellectual and enterprise achievement juxtaposed against the cumulative effects of decades-long socioeconomic decline. Yet, multiple systemic factors and related disparities prevail in the region. The City of Tuskegee, in particular, boasts a number of historically black institutions, cultural icons and intellectual achievements. Highly recognized icons include the world-renowned Tuskegee Institute (now Tuskegee University) and the famed Tuskegee Airmen, who served the country during periods of war and peace. On a more poignant note, the rich legacy of achievements during the early years of the Tuskegee Veterans Administration Hospital are too often overshadowed by the infamous, and highly publicized, syphilis research studies [14].

While taking into consideration the disparity factors highlighted above, a foremost concern for the region involves insufficient access to health care-particularly emergency and specialty services. Tuskegee has not had a full-service hospital for the public since the closing of John A. Andrew Hospital, located on the campus of Tuskegee University [15]. In fact, at one point Tuskegee/Macon County had three hospitals: one for the county, one for the public, and one for veterans. Each, over time, either closed or downsized significantly. Health care was a main economic driver for the community. As is so often the case in communities impacted by the loss of a rural hospital [16], 
the facility's closing precipitated a slow deterioration of the community due to a loss of jobs, population and no viable economic replacement.

The Tuskegee Veterans Administration (VA) hospital was a major, and historical, source of employment and served as a cornerstone of economic, intellectual, and public health innovations and stability. The hospital provided an aggregate of more than 2,000 employees and 23 medical services with training programs for nurses, medical doctors, psychiatrists, rehabilitation specialists, and other medical personnel. Over time, the institution expanded in scope to include medical, psychiatric, and rehabilitation services for African American soldiers who served in World War I as well as World War II, Korean and Vietnam War veterans. Following a directive from President Dwight D. Eisenhower in the early 1950s, the hospital integrated and services were available to both black and white former soldiers [17]. Under a direct order from President Clinton to cut costs, a 1996 merger between the Tuskegee VA and the Montgomery VA resulted in unfavorable economic impacts-affecting not only the Tuskegee VA hospital proper but surrounding cities and counties as well. As a consequence, major job losses occurred in a community previously dependent upon the VA hospital as a source of employment for almost 100 years. Renamed the East Campus of the Central Alabama Veterans Health Care System, the Tuskegee facility complex joined the National Register of Historic Places in 2012 [18].

\section{A Rural Underserved Population: Response to Prevailing Issues}

Preliminary assessments, augmented by the literature and empirical observation, suggest that broad-based, systemic, and sustainable efforts are needed in Macon County and surrounding Black Belt counties to bring about socioeconomic parity and enhance population health outcomes. The "Enhancing Rural Population Health Care Access and Outcomes through the Telehealth EcoSystem" model is an initiative emanating from the visionary platform of the Tuskegee Macon County Community Foundation, Incorporated (TMCCF), a regional nonprofit in partnership with Westat (a social science research corporation) and A2D, Inc. (a telecommunications/engineering/open access carrier). TMCCF and Westat formed a partnership in early 2014 to collaborate on a shared vision for active pursuit of rural health and community and economic development (CED) initiatives in Macon County, Alabama, and this partnership subsequently evolved to include A2D, Inc., in late 2014.

Two guiding theoretical frameworks-Community \& Economic Development (CED) and Collective Impact — and the introduction of intranet and telemedicine technology helped shape the conceptualization and implementation planning for the Telehealth EcoSystem ${ }^{\mathrm{TM}}$ model. As a catalyst for reform, the Telehealth EcoSystem ${ }^{\mathrm{TM}}$ model (see Figure 1 below) offers a holistic crosssector mechanism for health and social services delivery, digital connectivity, interoperability and technology infrastructure enhancement. The schematic highlights the underlying impacts of social determinants in population health outcomes and aligns with elements of the RWJF County Health Rankings \& Roadmaps (CHR\&R) Model [19].

Knowledge of the region's historical context offers a deeper understanding of Tuskegee Macon County's protracted period of socioeconomic decline. Accordingly, the collaborative team focused on the importance of understanding health indices and health care within a local context and explored avenues to address the underlying causes of disparities within and across geographical 
areas. Predicated upon best practices in health care, evaluation research, health technology and collaborative engagement, the Telehealth EcoSystem ${ }^{\mathrm{TM}}$ model is designed for implementation in iterative phases. The focus of the effort is to strengthen and expand existing health systems; improve technological infrastructure; and foster sustainable, community networks that drive change.

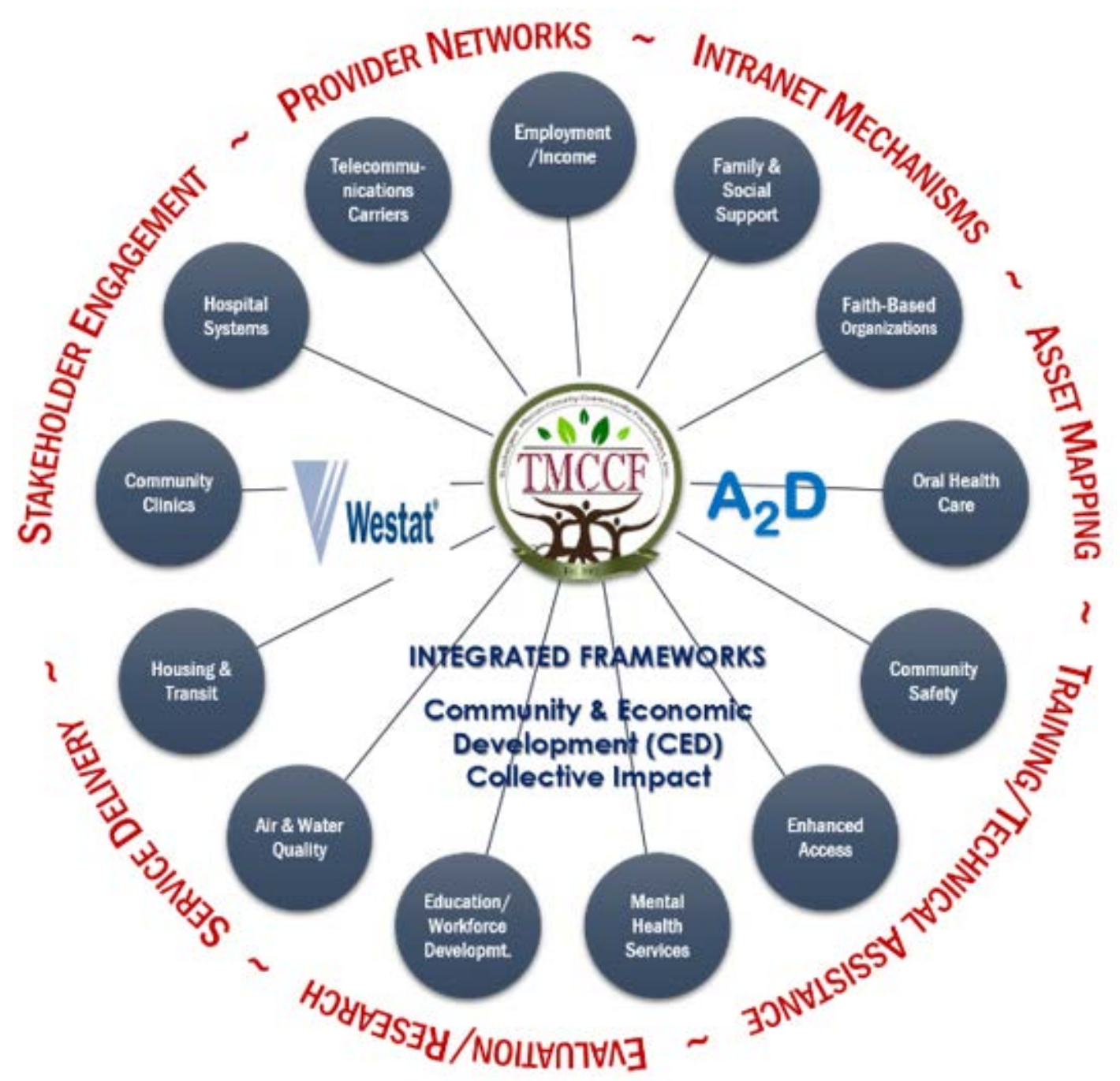

Figure 1: Telehealth Ecosystem ${ }^{\mathrm{TM}}$ Modell - Social Determinants of Health Factors

In Macon County, citizens who are relatively poor and suffer from chronic diseases are more likely to not visit their doctor regularly and wait until they have an emergency to get proper medical attention. Without a hospital, such residents rely primarily on local clinics to provide primary health care services. Most of Macon County's citizens have to commute 25-40 miles to the nearest hospital in neighboring Lee or Montgomery counties to get suitable specialty acute, emergency and follow-up care. The average fixed/low-income patient simply cannot justify spending the time/money/resources to commute long distances to the nearest hospital and wait hours solely for Online Journal of Public Health Informatics * ISSN 1947-2579 * http://ojphi.org * 10(2):e218, 2018 
a 30-minute medical check-up [20]. Because there is no hospital available within a reasonable proximity to this rural economically disadvantaged county, a viable alternative is to deploy technology solutions. Applications such as telemedicine [16], tele-dentistry [5], and eMobile health can facilitate access to medical care and help lower the overall cost of health care while improving the quality of service delivery and access to appropriate specialists. Just as important, there is a growing awareness among medical providers of the viability of electronic data platforms such as EHRs and health exchanges, health informatics applications and technology-related mechanisms for improving population health outcomes [5].

To address this problem, TMCCF and its core partners embrace technology-enabled care such as telehealth and mobile health applications which aligns with best practices and emerging solutions in the relevant literature. A recent School, Health \& Libraries Broadband Coalition (SHLB) website article highlights the viability of local and regionally based telecommunications access initiatives. The article recommends "community owned internet infrastructure through municipalities, public utilities, co-ops, or public private partnerships. ...Community ownership can be easier and more profitable when telehealth and telemedicine is a primary goal of the network." ${ }^{24}$ Telemedicine can deliver care to patients regardless of their physical location. It is cost effective not only to families, but hospitals and clinics as well. Research has shown that patients who receive such care are more likely to have better health outcomes and are less likely to be admitted or readmitted to the hospital, thereby curtailing unnecessary expenditures of funds and personnel through the misuse of emergency hospital services.

The Telehealth EcoSystem ${ }^{\mathrm{TM}}$ model's sequential development process consists of three phases. Phase I entails incremental tailored development and expansion of a health and human service provider network to support the Telehealth EcoSystem ${ }^{\mathrm{TM}}$ model initiative. Initial Phase I efforts, to date, are yielding noticeable gains in cross-sectorial engagement including awareness building and outreach and partnership development, along with a vertical network of organizational participants. Slated for implementation in Phase II is an intranet mechanism that utilizes multiple technologies and is a critical second stage component of the broad-based Telehealth EcoSystem ${ }^{\mathrm{TM}}$ model. This will incorporate intranet technologies to facilitate equalitarian access to information [21] and services in underserved communities. Expanded iterations of the Telehealth EcoSystem ${ }^{\mathrm{TM}}$ model are slated for Phase II of the developmental process.

With an ever-evolving industry and regulatory environment to consider, Phase III will focus on replication and sustainability with an aim at harnessing the technical capacity to communicate, analyze, and disseminate user-centered multi-sector models for service provision as well as costeffective access and services. By virtue of its proposed configuration, upon full implementation, the Telehealth EcoSystem ${ }^{\mathrm{TM}}$ model will provide a platform to design, test, and evaluate the risks and rewards of locally conceived and/or replication of evidence-based approaches to rural health systems.

Phase I remains in the developmental stages and is the focus of this article. The Telehealth EcoSystem $^{\mathrm{TM}}$ model will evolve along a continuum, and a series of initiatives are also projected in future phases to support job creation in the health care, education, and housing sectors, along with interoperability connectivity for law enforcement and emergency first responders, in communities throughout Macon County. It will bring also media to the people and help transcend Online Journal of Public Health Informatics * ISSN 1947-2579* http://ojphi.org * 10(2):e218, 2018 
transportation, digital connectivity and social barriers that might hamper some recipients. The Telehealth EcoSystem ${ }^{\mathrm{TM}}$ model will serve as a virtual community technology network that can be deployed to schools, community/youth centers, neighborhood associations, and other centrally located sites throughout the city of Tuskegee and the Macon County region. Satellite media centers can be equipped with a live television broadcast line and expansion capabilities with the addition of supplemental equipment and e-learning applications.

\section{The Core Partners}

The Tuskegee Macon County Community Foundation (TMCCF) was founded in October 2002 and reorganized in June 2012 with the new mission of enhancing the quality of life in disadvantaged communities in rural and urban areas. Currently, a particular focus is on a rural area region that includes the city of Tuskegee and other communities in Macon County. It sees as its major goals developing appropriate partnerships that address critical issues and challenges in disadvantage communities, and building and sustaining philanthropic capital. TMCCF sees its fundamental responsibility as facilitating research and documentation as a means of improving lives by investigating cause and effect so that, where appropriate, models can be replicated in other economically stressed communities. Consistent with its mission, TMCCF plays an integral role in marshalling resources, both people and financial, to address a community's needs such as the reduction of health disparities. Community foundations have been recognized as vital champions in revitalization efforts in resource-poor areas, especially in southern communities [22-24]. As a community foundation, TMCCF leverages its expertise and relationships with local, state, and national stakeholders to convene and engage key decision makers in dialogue and action-oriented planning focused on capacity-building, impacts, and outcomes. TMCCF also engages in outreach to diverse stakeholders to collaborate on the development of a strategic agenda for community and economic development, particularly in rural and urban poor communities. To meet the goal of cost-effective health and human service delivery in Macon County, TMCCF engaged Westat and A2D as critical partners in meeting the health care challenges of the Tuskegee Macon County region; this collaboration evolved into the Telehealth EcoSystem ${ }^{\mathrm{TM}}$ model.

Established in 1963, Westat is a nationally acclaimed social science research corporation with a rich history of conducting multisector evidence-based research and evaluation projects of national and global significance. The company's portfolio is varied, spanning a range of health, human service, and socioeconomic domains, including those within the health disparities and health equity arenas. Many of these efforts include studies that have contributed to the advancement of health equity and population health outcomes. Within Westat, the Center on Health Disparities \& Health Equity Research (hereafter, "the Center”) engages in transdisciplinary research and works with the Center's resource network of diverse partners. The Center provides technical assistance and project development consultation with a focus on planning, stakeholder engagement, and information dissemination/project replication capacities. In doing so, the Center focuses on evidence-based practices and innovations that have proven helpful in reducing disparities and promoting health equity. The Center helps to foster communication and stakeholder engagement; share and exchange best practices and experiences to strengthen community-based programming; and advance the development of appropriate community-based tools and resources. The Center's guidance on performance measure development helps shape a "real world" analytics platform so that the Telehealth EcoSystem ${ }^{\mathrm{TM}}$ model can be meaningfully assessed by policy, funding and Online Journal of Public Health Informatics * ISSN 1947-2579* http://ojphi.org * 10(2):e218, 2018 
regulatory decision makers. Westat has been charged with developing an evaluation/assessment methodology that will provide clear insight into the Telehealth EcoSystem ${ }^{\mathrm{TM}}$ model in preparation for replication in both rural and urban underserved communities with low socioeconomic indices.

A2D, Inc., a competitive local exchange carrier (CLEC), is on the forefront of bridging the digital divide in rural and low-income urban areas. A2D is uniquely able to connect citizens who can't afford internet access directly to community-based content, services and resources, without the internet. By removing the burden of affordability, community-based resources can now focus on providing services (in person and remotely) to all at-risk citizens. As a result, the fundamental goal of the collaborative team effort is developing replicable strategies to help multi-sector entities deliver social services across a no-cost digital medium (intranet) to help mitigate socioeconomic disparities. Central to this thrust is enabling Macon County's health care provider resources to identify and secure public-private funding resources to: a) modify existing programs; b) establish centralized data sharing and analytics depositories; and c) help analyze impact data to help refine how health resources can be delivered effectively to all citizens to enhance population health outcomes. A2D's network model has endured intensive vetting by a multitude of federal, state and municipal agencies. As such, A2D has maintained a focus on making connectivity available to all citizens regardless of their economic status as well as working with social service providers to help them leverage the network to deliver enhanced services. Through the introduction of technology as an equalizer, the Telehealth EcoSystem, powered by A2D's network, represents a realistic paradigm for digital connectivity in health care and human services delivery.

Additional early key stakeholders and organizations included the Macon County Health Care Authority, the Tuskegee Macon County Community Development Corporation (CDC), Southern Christian Leadership Foundation (SCLF), Tuskegee University College of Engineering, the Tuskegee University Graduate Program for Public Health, the National Association of Nurses, Tuskegee Chapter, the Retired Nurses Association, the Community Hospital of Tallassee, the Telehealth Work Group of Alabama, Tuskegee University Bioethics and Medical Research Center, and the Department of Psychology and Sociology, Tuskegee University. All were among key collaborators in strategic planning and project development.

\section{Methods and Approach}

The theoretical frameworks and methodological approach were based on best practices from the literature, empirical observations and real-world experiences deemed successful in enhancing rural population health outcomes. TMCCF, Westat's Center on Health Disparities \& Health Equity Research, and A2D embraced a community and economic development (CED) framework with an unwavering fidelity to addressing social determinants of health. Augmentative theories such as organizational development, dissemination and adoption, and systems thinking align with the core partnership's objectives. A combined CED framework and collective action framework overlay was subsequently adopted. The overlay of an integrated CED and Collective Impact framework also helps to acknowledge the relationships among economic distress, social determinants of health, the geo-political landscape, and the needs assessments/asset mapping required to move from concept to action and sustainability. This composite approach currently drives the Telehealth EcoSystem $^{\mathrm{TM}}$ model's rural initiative. 
In rural America, the correlation between local health care systems and the vitality of the community is strong, and high-quality health care indices can serve to leverage economic and community development initiatives [25]. In this context, population health status is viewed as an economic engine [26] — and can be a reciprocal driver for helping to bring about health equity. Health care industry efforts can also serve as a bridge between diverse sectors in CED initiatives. Community development has been operationally defined as a "set of processes or efforts to create community change at the local level . . . increasing awareness of issues ... and enhancing community member participation in addressing these issues." [27] A traditional CED approach offers strategic investments on a competitive merit basis to support economic development, foster job creation, and attract private investment in economically distressed areas.

Correlate concepts often associated with both CED and Collective Impact frameworks include culture and community engagement, community organization, community participation, capacity building, constituent engagement, community empowerment and coalition building [28]. Initially introduced in the United States in 2011 by the foundation consulting firm FSG, the Collective Impact concept "provides a useful framework for community change and is situated within the broad frame of collaborative efforts focused on systems and policy change." [29] The Collective Impact framework is increasingly being applied to address socioeconomic disparities, and the concept received wider dissemination in the literature in a Stanford Social Innovation Review Winter 2011 article [30]. The Collective Impact approach is described as "the commitment of a group of important actors from different sectors to a common agenda for solving a specific social problem.” In differentiating Collective Impact from other forms of collaboration, the Stanford Review authors contend that even though the "social sector is filled with examples of partnerships, networks, and other types of joint efforts," this approach is both distinct and flexible in format.

The core partnership team embraced the Collective Impact framework as an overlay to the foundational CED framework, as this augmentation underscores TMCCF's efforts as the regional anchor organization. Supporting backbone infrastructure is essential to ensuring the collective impact effort maintains momentum and facilitates impact [31]. A defining feature of the Collective Impact framework is the utilization of a backbone, or anchor, organization-a separate entity dedicated to coordinating the various dimensions and collaborators involved in initiatives. Moreover, fundamental principles of the Collective Impact framework highlight the relevance of a common agenda, performance measurement development, sustainable activities, ongoing dialogue, and having a core anchor, or nexus, to catalyze the efforts [32].

Case studies of select Collective Impact framework project applications underscore the vital role played by anchor institutions. The literature emphasizes the importance of "nonprofit management organizations that have the skills and resources to assemble and coordinate the specific elements necessary for collective action to succeed ... and that power of collective action comes not from the sheer number of participants or the uniformity of their efforts, but from the coordination of their differentiated activities through a mutually reinforcing plan of action.” [30] Two leading Canadian-based organizational proponents of the Collective Impact framework and Adaptive Leadership concepts, the Tamarack Institute and Collaboration for Impact, contend that Adaptive Leadership principles are compatible with complex systemic issues: "Adaptive problems . . . are complex ... reaching an effective solution requires learning by the stakeholders involved in the problem, who must then change their own behavior in order to create a solution.” Adaptive Online Journal of Public Health Informatics * ISSN 1947-2579* http://ojphi.org * 10(2):e218, 2018 
Leadership proponents contend that "the role of leading and coordinating collaborations is vastly different ... One requires us to respond, the other requires us to change.” [29]

\section{Augmentative Theories and Principles}

In addition to socioeconomic indices and geopolitical factors, human poverty is also contextual. Poverty and inequities cannot be measured only by statistical or quantitative methodology. Rather, they must be evaluated in concert with those conditions that drastically impact the very quality of one's existence - and which are not solely dependent on socioeconomic variables. Determinants of health reach beyond the boundaries of traditional health care. As such, life expectancy, health status, lack of addictions, personal security, emotional well-being, access to knowledge, environment, personal security, and political empowerment are equally crucial [21,33]. Social determinants of health refer to access to power, money, and resources and the conditions of daily life that affect health and well-being for groups of people [27].

Social determinants of health also correlate with the set of factors that contribute to the social patterning of health, disease, and illness the interrelationships among these factors determine individual and population health status [34,35]. Systemic and structural inequities [36] such as economic disenfranchisement, racial disparities, sub-standard environmental conditions, illness and workforce-related stressors can undermine one's overall health and well-being. Moreover, "Dealing with these conditions from a position of limited control can result in chronic stress on individuals, which is an underlying cause of many health conditions." [30] Education, housing, transportation, agriculture, and environmental sectors can be important allies in improving population health. Accordingly, interventions that target multiple determinants of health are most likely to be effective.

Implementation planning and assessment processes, such as asset mapping, focus groups and participatory forums, align with emerging and best practices for engaging community leaders in participatory dialogues that are designed to enhance the information landscape [37,38]. Social constructs such as Lewin's Model of Change [39] also informed the conceptualization of the Telehealth ${ }^{\mathrm{TM}}$ EcoSystem model—particularly regarding community engagement and health equity promotion aspects. Lewin's model offers avenues to combat barriers to intersectoral collaboration via a "process known as unfreezing . . . by understanding the "professional logic" of potential partners ... pointing out the benefits of partnership to them." This methodology, in essence, helps in "overcoming inertia and dismantling the existing mindset." [40]

\section{Perspectives on Digital Connectivity in Reducing Health and Socioeconomic Disparities}

- The Telehealth EcoSystem ${ }^{\mathrm{TM}}$ model focuses on strengthening community capacities as a critical variable for disparities reduction and promotes discerning media access and consumption. The model also embodies select recommendations from a Knight Foundation Commission Report [38] on media communications, information dissemination and civic engagement, which called for: a) development of systematic quality measures of community information ecologies; b) assessment of impacts on social outcomes; c) support for information providers in reaching local audiences; d) dissemination of quality content through diverse media (e.g., 
mobile phones, radio, public access cable, new platforms); e) provision of continuous affordable high-speed internet service; and f) engagement of citizens in acquisition and knowledge sharing within and across social networks.

- A Stanford Social Innovation Review article titled Tech and Innovation to Reengage Civic Life provided the following caveats regarding the relevancy of information access to socioeconomic parity and community well-being: a) "Sometimes even the best-intentioned policymakers overlook the power of people. And even the best-intentioned discussions on social impact and leveraging big data for the social sector can obscure the power of everyday people in their communities," and b) "Well-structured civic engagement creates the space and provides the tools for people to exert agency over policies. When citizens have concrete objectives, access to necessary technology (whether it's postcards, trucks, or open data portals), and an eye toward outcomes, social change happens.” [41]

- A Federal website blog article titled Advancing Health Equity in the Digital Age [42] highlighted the potential for health information technology (health IT) to improve chronic disease management and care coordination efforts as well as mitigate against health issues that disproportionately impact communities of color. Citing “. . . lack of access to quality, preventive health care, cultural and linguistic barriers, and limited patient-provider communication as factors that aggravate health disparities," the author asserts that “ . . . limited financial capital and lack of systems that can communicate effectively with each other widen the digital divide between providers and other clinicians who provide health services to a significant number of minority communities."

- Former Federal Communications Commission (FCC) Commissioner Mignon L. Clyburn spearheaded the establishment of the Connect2Health FCC Task Force, which is "a dedicated, interdisciplinary team, focused on the intersection of broadband, advanced technology, and health. Clyburn's remarks at a recent NHITHIMSS Leadership Conference highlight the digital divide and resulting impacts on population health. Clyburn asserts that “... broadband deployment ... provides the necessary foundation for creating the gateway to new and sustainable models for meeting longstanding health goals. . . . These efforts can further spur the U.S. economy and help to close the digital divide, while at the same time be an oasis in a health care and wellness desert. ... The data clearly shows that the picture of health is vastly different in connected communities versus those in digitally-isolated areas. This holds true when it comes to access to care, quality of care, and health outcomes ... almost half of U.S. counties are 'double burden' counties, where there are elevated levels of chronic disease and lower levels of broadband connectivity. Perhaps it's time for us to evolve our thinking, grow our vision, and create a 'broadband health safety net,' for underserved groups in America.” [43]

\section{Results}

Formalization of the Telehealth EcoSystem ${ }^{\mathrm{TM}}$. The ecological network concept emerged as the Macon County Telehealth EcoSystem ${ }^{\mathrm{TM}}$ in 2014. Development of a charter served to codify and define the ecosystem's mission, membership, and operating guidelines. With its work undergirded 
by the integrated frameworks of CED and Collective Impact, the developing Telehealth EcoSystem $^{\mathrm{TM}}$ model embraced collaborative processes that reflect a common vision, commitments to share information and resources, and active participation in contributing to ongoing developmental and capacity building efforts.

Overall impacts for Phase I, to date, include noticeable gains in cross-sectoral engagement, including awareness building, outreach, and partnership development. Several processes represented milestone information and dissemination opportunities and a pattern of meaningful results-oriented impacts in the evolution of the Telehealth EcoSystem - Health Equity Roundtable Forum and TMCCF Asset Mapping activities. These initiatives yielded a variety of meaningful results-oriented impacts that reflect opportunities for facilitating and disseminating vital information across disciplines, venues, and audiences in the health and human service sectorswith an emphasis on what might be done jointly through expanded collaborative efforts.

Telehealth ${ }^{\mathrm{TM}}$ EcoSystem model derivatives in expanded phases are projected to include evaluation studies, development of regional CED performance measures, publications, conferences and dissemination of tools that inform policy and decision-making. Phases I through III expansion plans include:

- Programs such as telehealth, distance learning, social services and virtual workforce training will be highlighted;

- The intranet expansion will be designed to incorporate multiple stakeholders and organizations operating in tandem within an umbrella intranet and telehealth ecosystem to increase efficiency, effectiveness, and scale; and

- Participating entities will be connected to each other, to regional/state/national resources, and to the internet at minimum costs. The development process will address not only the installation of digital connectivity and intra/internet equipment for telehealth, but will address other issues that are important to developing a wholesome environment to live, work and play.

The core partners used a tiered and phased approach to guide the developmental work of the Telehealth EcoSystem and operationalize processes in support of its mission. Methods used in Phase I of the Telehealth EcoSystem ${ }^{\mathrm{TM}}$ include the activities detailed in the following sections.

\section{Federal, State, Local Government, and Corporate Entity Consultation on Telehealth Initiatives}

Understanding the telehealth landscape at the Federal, state, and local levels was fundamental to codifying strategic plans and spurring the evolution of the Telehealth EcoSystem's approach to telehealth services in Macon County. Selected outcomes from these efforts included:

- Receipt of technical assistance from various Health Resources and Services Administration's (HRSA's) telehealth program offices;

- Receipt of technical assistance support from Southeastern TeleHealth Resource Center (SETRC); 
- SETRC intervention led to an invitation for TMCCF to join the Alabama Partnership for Telehealth (APT) state workgroup; and

- Confirmation of financing and reimbursement guidelines and requirements from the Alabama Office of State Medicaid and Blue Cross Blue Shield Corporate offices. Among other consultations in the private sector included exploration of various care coordination service models, such as the Pathways Community HUB Model. Other organizations played a key role as informants about the targeted population and the realties facing them. This included but is not limited to the Retired Nurses Association, Macon County Nurses Organization, Macon County Health Care Authority, Tuskegee University Department of Sociology and Psychology, Tuskegee Housing Authority, Macon County Ministers Association, Tuskegee Medical and Surgical Center, and A2D. All of the named organizations had a major role as part of the strategy to improve connections of at-risk populations to health and human services needed to optimize their access to care and subsequent health outcomes.

\section{Public and Private Sector Partnerships/Engagement of Diverse Stakeholders}

As the champion of this effort, TMCCF recruited and engaged multi-sector provider and stakeholder organizations as members of a vertical network. As the membership of this network expanded, its operations increasingly aligned with those of a coalition. Specifically, operations focused on embracing a common vision and using collaborative decision-making processes to inform our strategic approach.

Other information dissemination activities were conducted using various forums and media (i.e., radio talk shows, printed flyers, public TV) to heighten awareness of the problems that providers and researchers identified as needing to be addressed. Information dissemination and community outreach efforts were conducted to provide the community with an opportunity to have their voices heard in decision-making. Such conversations helped align the preliminary assessments with the community's priorities. At the same time, the community would have an opportunity to gain insight into how the telehealth initiative could result in a range of benefits that were not limited only to transforming the service delivery system, but also to improving the quality of patient-centered care and reinvesting in the local economy.

\section{Formal Workgroup Development}

Cross-sector discussions were achieved through participation in local organizational meetings, a national roundtable series, community conversations, and inviting unique perspectives drawn from the diverse disciplines that they represented. Engaging EcoSystem members in an asset-based resource mapping activity to identify available resources and service gaps was an important step in model development. 


\section{Health Equity Roundtable Event IV}

Dissemination of Information and Outreach to the Community. Engaging the community was pivotal to this effort in light of the localized nature of the telehealth initiative. The community's participation in a televised roundtable event on April 26, 2017, co-sponsored by Westat's Center on Health Disparities \& Health Equity Research and the Rockville Institute, featured the Tuskegee Macon County Community Foundation (TMCCF) and the National Center for Bioethics in Research and Health Care at Tuskegee University as collaborators. This event, titled "Innovations in Health Policy \& Practice: A Conversation in Reinvesting in Rural Health,” explored processes by which ideas and methods transform into policy and practice within CED. The Collective Impact Roundtable IV culminated Westat's national roundtable series. This approach was perhaps the most useful among the previous events because it directly engaged health care providers, citizens, government officials, university students and faculty as well as ordinary citizens in a rich dialogue for the first time in generations.

The forum provided a unique and compelling "point of entry" for audience engagement and dialogue. It brought together a diverse group of 70 or more local leaders, stakeholders and laypersons men and women of all ages from the public, private and nonprofit sectors, including representatives from local and state government, media, businesses, academia, nonprofits, universities, health providers and schools. Discussions highlighted current and emerging programs for addressing health disparities and current and emerging programs for addressing health disparities and health equity. The roundtable events served as a motivation for presenters, facilitators and attendees (virtual and on-site) to explore other major programs and sectors as potential partners and to examine models, strategies, and tools for use in existing cross-sector programs.

Community processes are most successful when they encourage the richest possible dialogue among participants [37]. An interactive, multi-sector, community-based conversational forum was deployed to spawn momentum in anticipation of action-oriented responses. The insights gleaned from this this event provided a great platform for civic engagement and action. It explored processes by which ideas and methods transform into policy and practice within CED and Collective Impact frameworks. The robust dialogue that ensued from session IV served as a catalyst for future brainstorming, strategic planning and focused reflection. Capturing new ideas in real time is one way to sustain the momentum of the changes that people want in their communities. Multiple accounts to date continue to inform us that roundtable session IV participants left the convening feeling energized, and hopeful, about the opportunities ahead even in the face of formidable challenges. As noted earlier, while a rich and storied history provided a historical context for this event, Macon County continues to face significant socioeconomic and population health challenges with insufficient resources to address these deficits. Yet, the community abounds with creativity and commitment to transform the current state of affairs. This roundtable represented an opportunity for a rural community to articulate health challenges as well as make a cursory assessment of its resources, which would inform action steps. 
With TMCCF's leadership, local stakeholder engagement for Event 4 began with recruitment of innovators to participate as panelists and enlisting local media personalities to help educate the community about the event and planned agenda topics. Radio and community television promotional events were held leading up to event. Outreach efforts were augmented by TMCCF through various academic departments at Tuskegee University as well as TMCCF/Westat inperson meetings with local Tuskegee leaders and with the Director of the Tuskegee University's archives. Collectively, these efforts provided additional historical context for roundtable preparatory activities and information for ongoing strategic planning efforts. These preliminary conversations also helped to heighten awareness and encourage community participation in the event.

Westat and TMCCF met with A2D to gain insight and understanding about the role of technology and how it can be deployed to reach the goals of connectivity to provide a comprehensive healthcare service for a rural community. Several meetings were held in Atlanta, GA, in the office of A2D to gain hands-on exposure to the process by which underserved communities can receive direct benefits through broadband connection. These sessions brought into sharp focus how the Telehealth EcoSystem can be a viable and practical model for health service delivery.

\section{Health Asset Mapping Group}

A major outcome of the roundtable event was the development of a Health Asset Mapping Group. The Asset Mapping Group consisted of an informal gathering of health care providers who engaged in participatory dialogue to share their programs, projects, activities and concerns. What started out as a one-time meeting to develop a formal description of health care resources became a regular monthly meeting. Participants included retirees from the health care profession. Everyone felt that it was important to play a part in the revitalization of the City of Tuskegee and Macon County at large and acknowledged that having reliable and competent health care services was critical in making this rural community a better place to live.

The group begin meeting monthly in June 2017 via rotational tours of their provider facilities, sharing programs, services and resources. One of the critical outcomes of the Mapping Group is learning about each individual, thereby engendering trust. Gaining trust fostered participatory engagement and collaboration-a signature requirement in developing the Telehealth EcoSystem. The Mapping Group has become the foundation for initiating the Vertical Network and utilizing the Collective Impact theory.

\section{Technical Assistance: Needs Assessment, Identification of Effective Practices, Performance Measurement}

The Center provided guidance on performance measure development and helped shape a real world analytics platform for meaningful assessment of the Telehealth EcoSystem ${ }^{\mathrm{TM}}$ model and dissemination of outcomes for review by policy, funding and regulatory decision makers. The importance of community context in health and social science research and evaluation studies is highlighted in the summary proceedings from a workshop titled "Applying a Health Lens to Decision Making in Non-Health Sectors.” The sparseness of the population in rural communities can make it more difficult than in urban areas to gather data and expand programs that address 
health disparities [3]. This is particularly so in scenarios involving randomized trials and control studies.

Our needs assessment approach is flexible and predicated upon community-based participatory research methods undergirded by digital connectivity and telehealth applications. A shared measurement system is a fundamental element of the Collective Impact framework: "Agreement on a common agenda is illusory without agreement on the ways success will be measured and reported." [30] A publication from the Institute of Medicine emphasizes the "complex interactions between these factors"; the relevance of adaptive management "taking actions and defining metrics, and then making adjustments to those actions based on feedback over time"; and noting "Impact assessment is not about making definite predictions." [44]

Examples of Westat-led technical assistance activities conducted in Phase I and slated for Phases II through III include:

\section{Phase I}

- An environmental literature scan

- Analysis of secondary demographic and health data to document need

- Website analytics: website performance metrics (including data on web traffic and/or click-throughs)

- Social media analysis: Assessment of reach, engagement and/or sentiment expressed on social media platforms (e.g., Facebook, Twitter, Flickr and YouTube)

- Online polls: Questions delivered to readers or users to gather data on knowledge, attitudes, or behaviors.

- Identifying and creating structures for communication and collaboration among stakeholders

\section{Phases II-III}

- Process and Outcome Evaluation

- Intervention Research

- Service Delivery Research

\section{Discussion}

The Telehealth EcoSystem ${ }^{\mathrm{TM}}$ model concept emanated from TMCCF's fundamental vision for restoration and socioeconomic renewal in Macon County and was facilitated by partnership engagement. The model is a dynamic, evolutionary approach to embracing health informatics and related technologies as vital elements in wide-scale systems change. Envisioned as a vehicle to address health disparities, the Telehealth EcoSystem ${ }^{\mathrm{TM}}$ model advances multi-sector engagement, implementation planning and novel intranet technologies for communication and interoperability between public and private health and social service organizations. Informed by best practices in health care and information technology, business, health care and human service sectors derive mutual benefits from the alignment of resources for digital connectivity and access [45]. The Telehealth EcoSystem ${ }^{\mathrm{TM}}$ model's Phase II Intranet mechanisms will enable provider networks to: 
- Explore collaboration as content experts;

- Engage in mutually sponsored health equity promotional efforts;

- Develop health equity products for dissemination within the digital community;

- Explore project-based partnerships; and

- Explore participation in expanded internal and external organizational networks.

Promoting individual and organizational engagement entails generating opportunities and motivation for involvement. Fulfillment of basic information needs is paramount, including information about jobs, housing, taxes, safety, education, transportation, recreation, entertainment, food, shopping, utilities, child care, health care, religious resources, and local news. Seeking to contribute to overall information ecology, our Telehealth EcoSystem model embraces health and media literacy best practices [46] and aligns with systems theory and information dissemination constructs. A definitive report from the OECD Directorate for Employment, Labour and Social Affairs recommends that legislative strategies aimed at socioeconomic disparities reduction should be grounded in policies that foster wide and equal access to education, information and highquality public services [47].

Current implementation planning strategies for the Telehealth EcoSystem ${ }^{\mathrm{TM}}$ model are derivatives of a shared vision for restoration of a once-vibrant Tuskegee Macon County community. The team's approach aligns with promising and emerging best practices in stakeholder engagement, care coordination, systems thinking, dissemination and adoption of theories and health equity promotion: "When a wider vision incorporating concepts of well-being and taking a more societal view is deployed, the patterns of relationships with other sectors change, reflecting the need for the work of the sector(s) to be ordered by the needs of people and not by sectoral objectives." [48]

The integrated CED framework/Collective Impact framework overlay enables sustainable change in the Tuskegee Macon County health care system by bringing together stakeholders from multiple sectors who may appear to have conflicting approaches but agree to set aside their personal or organizational agenda for the purpose of accomplishing an agreed-upon goal [49,50]. The advocacy is a holistic approach to problem solving, and it will take the minds and concerns of everyone working together diligently and consistently to solve the myriad issues and problems of health care in a rural community. This focus is particularly timely. In a University of Georgia publication titled “An Economic Analysis of Georgia's Black Belt Counties," authors Brigid Doherty and John McKissick highlight the demographics, health and socioeconomic disparities [11] indices that plague the Black Belt region. The academic literature reflects the Black Belt as an area of keen focus for public health, economic development and educational researchers, legislators and policy analysts ${ }^{.55}$

"The promotion of good health is necessary across the lifespan and cannot be achieved without joint efforts and partnerships with stakeholders." [1] Collaboration can provide opportunities for determining the catchment areas and groups for resources by: collecting data about specific deficits in specific services; creating differentiated strategies to address the identified catchment areas; developing resources for evaluating the success of strategies; spreading the word about those strategies that are shown to work; and sustaining the efforts of the collaborative. "Stakeholder engagement is very important in addressing the social determinants of health and health inequities ... Tackling health inequalities and ensuring equity from the start is an ambitious and Online Journal of Public Health Informatics * ISSN 1947-2579* http://ojphi.org * 10(2):e218, 2018 
complex task that requires coordinated action from a wide range of stakeholders . . . it requires shared responsibilities across sectors.” [1] Importantly, a collaborative can connect providers, share techniques for retaining workers, and identify promising practices in a range of areas.

The Westat Center on Health Disparities \& Health Equity Research is closely aligned with its core partners, TMCCF and A2D, Inc., regarding future research efforts to assess the impact and effectiveness of the Telehealth EcoSystem model and its associated frameworks. The team recognizes that while there have been major milestones accomplished to date, there is tremendous potential to help advance the field of telehealth and public health informatics. Rigorous study of our current efforts is necessary so that lessons learned may emerge and be used to inform the replication of innovative practices in other economically distressed communities. From all indications to date, this initiative portends development of a robust telecommunications infrastructure, quantitative and qualitative performance measures, enhanced population indices, and health informatics and health IT platforms to address the social determinants of health. These indicators are reflective of the partners' collective vision for enhanced population health outcomes. To this end, we plan to use future research to address the following limitations of our current efforts:

- The telehealth ecosystem is in the developmental stages in Tuskegee, Alabama. While the ecosystem model incorporates several evidence-based practices, formal research involving assessing its effectiveness and impact in this specific community has not yet been conducted.

- The current efforts have not yet used dissemination and implementation science research to validate the telehealth ecosystem approach to systematically address health equity.

- Scientific investigations are needed to provide a foundation for assessing the internal and external validity of the innovation for widespread adoption in other communities that have a focus on addressing health equity.

\section{Conclusion}

Over a period of years along a continuum, stakeholder engagement, implementation planning, technical assistance, and organizational collaboration laid the groundwork for a virtual Telehealth provider network infrastructure (Telehealth EcoSystem) to facilitate future digital connectivity and health services delivery.

We have determined that an intranet-based solution is the most cost-effective and efficient solution for this rural community. This preliminary work will inform future expansion of the Telehealth EcoSystem's virtual intranet mechanism through its multi-dimensional operational features and functions with particular relevance to health informatics applications. Examples of its anticipated uses include enhanced medical care coordination by clinicians, quality of care assessments for quality improvement initiatives by clinical provider organizations, disease surveillance by public health agencies, HIPAA compliant data management and access for clinical research and evaluation by the academic research community, and community engagement by communityacademic partnerships. 
The collective impact of these foundational action steps has helped to advance understanding of the needs and capacity of the rural underserved community population and the health centers that serve them, improve health outcomes, reduce health disparities, and increase access to health care for underserved populations. These formative steps will be pivotal to the Telehealth EcoSystem model's next phase of work. Key action steps during Phase II will involve leveraging the Telehealth EcoSystem's capacity using the intranet as a means to create a responsive system of health care for Macon County residents.

\section{Operational Definitions}

Black Belt counties. The Black Belt is a region in the southern United States. The literature notes that the term originally described the prairies and dark soil of central Alabama and northeast Mississippi and now references a broad agricultural region in the American South characterized by historical agriculture in the 19th century and a high percentage of African American residents.

Community (locality) development. Community development is a set of processes or efforts to create community change at the local level. It involves strengthening social ties, increasing awareness of issues affecting the community, and enhancing community member participation in addressing these issues [27].

Health disparities refer to differences in the existence and frequency of health conditions and health status among groups. Health disparities are referred to as health inequities when they are the result of the systematic and unjust distribution of these critical conditions. Health inequities are "avoidable inequalities in health between groups of people within countries and between countries (World Health Organization, 2010)." Health equity, then, is when everyone has the opportunity to "attain their full health potential" and no one is "disadvantaged from achieving this potential because of their social position or other socially determined circumstance.” [27]

Media advocacy. Media advocacy refers to the strategic use of print, broadcast, and social media to encourage social, economic, or environmental change.

Social determinants of health refer to access to power, money, and resources and the conditions of daily life that affect health and well-being for groups of people (Solar, Irwin, WHO 2010) [51].

Telehealth is generally defined as: "the practice of healthcare delivery using telecommunications technology including but not limited to diagnosis, consultation, treatment, transfer of medical data, education, dissemination of public health alerts and/or emergency updates." The term telemedicine, on the other hand, usually references a more specific "use of telecommunications technology to deliver clinical diagnosis, services and patient consultation."

\section{Financial Disclosure}

The authors have no financial or other interests to disclose. 


\section{Competing Interests}

The authors have declared that no competing interests exist related to this publication.

\section{Disclaimer}

The findings and conclusions in this manuscript are those of the authors and do not represent the official positions of WESTAT, The Tuskegee Macon County Community Foundation, A2D, Inc., or Health Marketing Concepts International.

\section{References}

1. First EU-wide stakeholder debate of the Equity Action. Together for health equity from the start. May 2012. Budapest, Hungary. Available from: http://www.health-inequalities.eu/wpcontent/uploads/2016/05/1_1_e_Documentation_1st_EU_debate.pdf

2. Commins J. Population health poses unique challenges in rural areas. Health Leaders. October 28, 2015. Available from: https://www.healthleadersmedia.com/strategy/population-healthposes-unique-challenges-rural-areas

3. Olson S, Anderson K. Achieving rural health equity and well-being: Proceedings of a workshop. National Academies of Sciences, Engineering, and Medicine. 2018. Washington, DC: The National Academies Press. Available from: http://nap.edu/24967

4. Sumners C. Why living in a rural area could be considered a health risk. Vital Record. Texas A\&M Health Science Center School of Public Health. June 19, 2017. Available from: https://vitalrecord.tamhsc.edu/why-living-in-a-rural-area-could-be-considered-a-health-risk/

5. Bolin JN, Bellamy G, Ferdinand AO, Kash BA, Helduser JW, eds. (2015). Rural Healthy People 2020. Vol. 1. College Station (TX): Texas A\&M Health Science Center School of Public Health, Southwest Rural Health Research Center. Available from: https://srhrc.tamhsc.edu/docs/rhp2020-volume-1.pdf

6. Alabama Black Belt Counties Map. Auburn University Scholarship/Resources. Available from: http://auburn.edu/scholarship/resources/AlabamaBlackBeltCounties.pdf

7. The Robert Wood Johnson Foundation (RWJF)/University of Wisconsin Population Health Institute (UWPHI). 2018 County Health Rankings Report Alabama. Available from: http://www.countyhealthrankings.org/app/alabama/2018/rankings/macon/county/outcomes/o verall/snapshot

8. United States Census Bureau. Income to Poverty Ratio. Macon County, AL. Available from: https://data.census.gov/cedsci/results/all?q=Macon\%20County,\%20Alabama\%20Income\%2 0and\%20Poverty\&t=Income\%20and\%20Poverty\&g=0500000US01087\&ps=search*suggest ions@false 
9. Tullos A. The black belt. Southern Spaces Journal. Emory University. April $19^{\text {th }} 2004$. Available from: http://southernspaces.org/2004/black-belt.

10. United States Census Bureau. Quick Facts, Macon County, Alabama, Available from: https://www.census.gov/quickfacts/fact/table/maconcountyalabama/PST045216

11. Doherty B, McKissick K. An economic analysis of Georgia's black belt counties. The University of Georgia, Center for Agribusiness and Economic Development and College of Agricultural and Environmental Sciences April 11, 2006. Available from: http://athenaeum.libs.uga.edu/xmlui/bitstream/handle/10724/18790/CR-02-

06.pdf?sequence $=1$

12. Robert Wood Johnson Foundation (RWJF), University of Wisconsin Population Health Institute. 2018 County health rankings for the 67 ranked counties in Alabama. Available from: http://www.countyhealthrankings.org/sites/default/files/state/downloads/CHR2018_AL.pdf $\sim$ http://www.countyhealthrankings.org/app/alabama/2018/overview

13. Federation of Southern Cooperatives/Land Assistance Fund. Available from: www.federation.coop

14. Reverby SM. 2010. Examining Tuskegee: the infamous syphilis study and its legacy. Chapel Hill, NC. University of North Carolina Press. Soc Hist Med. 23(2), 432-33. https://doi.org/10.1093/shm/hkq026

15. Rice MF, Jones W. The decline of black hospital and contemporary public policy in Public Policy and the Black Hospital: From Slavery to Segregation to Integration. Chapter 5: Greenwood Press. Westport, Connecticut. 1994 (p 101). Available from: https://books.google.com/books?id=puc6K2KGFBwC\&pg=PA101\&lpg=PA101\&dq=John+ A+Andrews+Hospital+in+Tuskegee, + Alabama\&source=bl\&ots=wA2RJSpfg\&sig=KnDCG cngDRrGlibh5_aOFq3Hqss\&hl=en\&sa=X\&ved=0ahUKEwj_puX0k8jbAhVDxVkKHevhD _o4ChDoAQg9MAU\#v=onepage\&q=John\%20A\%20Andrews\%20Hospital\%20in\%20Tusk egee\%2C\%20Alabama\&f=false

16. Texas A\&M University Rural \& Community Health Institute (RCHI). (2017). What's next? Practical suggestions for rural communities facing a hospital closure. Available from: https://www.rchitexas.org/

17. Rhodes G, ed. Director spells out history of Tuskegee VA during Eggs and Issues. The Tuskegee News. December 16, 2010. Available from: http://www.thetuskegeenews.com/news/director-spells-out-history-of-the-tuskegee-vaduring-eggs/article_a1d5ffe1-8fa0-5526-86bf-e89b8856a9fd.html

18. Tuskegee VA hospital listed on national historic register. The Tuskegee News. Tuskegee, AL. Apr 12, 2012.2 Available from: http://www.thetuskegeenews.com/articles/2012/04/12/news/doc4f85a190bbc64595347664.t $\mathrm{xt}$ 
19. The Robert Wood Johnson Foundation (RWJF), University of Wisconsin Population Health Institute (UWPHI). County health rankings \& roadmaps (CHR\&R) model. 2018 County health rankings report, Alabama. Available from: http://www.countyhealthrankings.org/explore-health-rankings/reports/state-reports/

20. Thompson L. When "access" becomes a barrier: The environment of health care accessibility. Vital Records News. Texas A\&M University Health Science Center. December 21, 2015. Available from: https://vitalrecord.tamhsc.edu/when-access-becomes-a-barrier-theenvironment-of-health-care-accessibility/

21. The media desert's project: executive summary. Available from: https://mediadeserts.wordpress.com/about/executive-summary/

22. Sacks EW. The growing importance of community foundations 2014. Lilly Family School of Philanthropy, Indiana University and the Charles Stewart Mott Foundation. Available from: https://philanthropy.iupui.edu/files/file/the_growing_importance_of_community_foundation s-final_reduce_file_size_2.pdf

23. National Association of Development Organizations Research Foundation. Collaborative leadership: partnerships between regional development organizations and community foundations. https://www.nado.org/wp-content/uploads/2012/07/collaborative-leadership.pdf

24. Schlegel R, Peng S. National Committee for Responsive Philanthropy and Grantmakers for Southern Progress (GSP). As the south grows, so grows the nation: executive summary. June 12, 2018. Available from: https://www.ncrp.org/wp-content/uploads/2018/06/As-the-SouthGrows-So-Grows-the-Nation-executive-summary.pdf

25. Rural Information HUB. Community vitality and rural healthcare. Available from: https://www.ruralhealthinfo.org/topics/community-vitality-and-rural-healthcare

26. Weinstein J, Geller A, Negussie Y, Baciu A, eds. National Academies of Sciences, Engineering, and Medicine. 2017. Communities in action: pathways to health equity (Chap 7: Partners in Promoting Health Equity In Communities). Washington, DC: The National Academies Available from: http://nap.edu/24624

27. Community Toolbox. Chapter 17. Addressing Social Determinants of Health in Your Community. Center for Community Health and Development at the University of Kansas. Available from: https://ctb.ku.edu/en/table-of-contents/overview/models-for-communityhealth-and-development/social-determinants-of-health/main

28. McCloskey DJ, McDonald M, Cook J. Heurtin-Roberts, Updegrove S, Sampson D, Gutter S, Eder M. Principles of community engagement (Chapter 1). Community engagement: definitions and organizing concepts from the literature. Centers for Disease Control Agency for Toxic Substances and Disease Registry Available from: https://www.atsdr.cdc.gov/communityengagement/pdf/PCE_Report_Chapter_1_SHEF.pdf 
29. Tamarack Institute for Community Engagement. Collective impact. 2018. Available from: https://www.tamarackcommunity.ca/collectiveimpact

30. Kania J, Kramer M. Collective impact. Stanford Social Innovation Review. Winter 2011. Stanford Center on Philanthropy and Civil Society. Available from: https://ssir.org/articles/entry/collective_impact

31. Collaboration for Impact. The backbone organization. Available from: http://www.collaborationforimpact.com/collective-impact/the-backbone-organisation/

32. Centers for Disease Control. Principles of community engagement: definitions and organizing concepts from the literature. $2^{\text {nd }}$ ed. NIH Publication No. 11-7782 Printed June 2011, Available from: https://www.atsdr.cdc.gov/communityengagement/pdf/PCE_Report_508_FINAL.pdf

33. Organization for Economic Co-operation and Development. Tackling high inequities: creating opportunities for all. June 2014. Available from: https://www.oecd.org/unitedstates/Tackling-high-inequalities.pdf

34. Centers for Disease Control and Prevention. Social determinants of health: know what affects health. January 2018. Available from: https://www.cdc.gov/socialdeterminants/

35. Brennan Ramirez LK, Baker EA, Metzler M. Promoting health equity a resource to help communities address social determinants of health. Atlanta: U.S. Department of Health and Human Services. Centers for Disease Control and Prevention. 2008. Available from: https://www.cdc.gov/nccdphp/dch/programs/healthycommunitiesprogram/tools/pdf/sdohworkbook.pdf

36. Powell J, Reece J, Rogers C, Gambhir S. Communities of opportunity: a framework for a more equitable \& sustainable future for all. The Kirwan Institute for the Study of Race and Ethnicity. Ohio State University. 2007. Available from: http://www.racialequitytools.org/resourcefiles/powell1.pdf

37. James L. Knight Foundation. Building stronger communities through information exchange: planning for action toolkit. Available from: https://www.knightfoundation.org/media/uploads/publication_pdfs/2011_KF_Community_I nformation_Toolkit.pdf

38. Harwood R. Assessing community information mlneeds: a practical guide. Washington, DC: The Aspen Institute. October 2011. Available from: https://www.knightfoundation.org/media/uploads/publication_pdfs/Assessing_Community_I nformation_Needs_10.6.11.pdf

39. Mind Tools. Lewin's change management model: understanding the three stages of change. Available from: https://www.mindtools.com/pages/article/newPPM_94.htm 
40. Second EU-wide stakeholder debate of the equity action. Together for health equity from the start. November 2012. Berlin, Germany. Available from: http://www.healthinequalities.eu/wp-content/uploads/2016/05/documentation_second_stakeholder_debate.pdf

41. Gilman H. 2015. Tech and innovation to re-engage civic life. Stanf Soc Innov Rev. 24(Nov), $\cdots$.

https://ssir.org/data_for_community_driven_solutions/entry/tech_and_innovation_to_re_eng age_civic_life\#.

42. DeSalvo K, Garcia N. Advancing health equity in the digital age. Health IT Buzz. Office of the National Coordinator (ONC) for Health Information Technology. Available from: https://www.healthit.gov/buzz-blog/from-the-onc-desk/advancing-health-equity-digital-age/

43. Clyburn M. Leveraging health IT to address health disparities: remarks of commissioner Mignon L. Clyburn NHIT-HIMSS leadership conference: Las Vegas, NV. March 7, 2018. Available from: https://www.fcc.gov/document/commissioner-clyburn-remarks-himss-2018conference

44. Wizemann T. (Rapporteur). Institute of Medicine. 2014. Applying a health lens to decision making in non-health sectors: workshop summary. Washington, DC: The National Academies Press. Available from: http://nap.edu/18659

45. The Aspen Institute. Informing communities: sustaining democracy in the digital age. Knight Commission Report. (A project of the Aspen Institute Communications and Society Program and the John S. and James L. Knight Foundation.) 2009. Washington, DC: The Aspen Institute. Available from: https://assets.aspeninstitute.org/content/uploads/files/content/docs/pubs/Informing_Commun ities_Sustaining_Democracy_in_the_Digital_Age.pdf

46. Hobbs R. Digital and media literacy: a plan of action. Knight Commission Report on the Information Needs of Communities in a Democracy. Washington, DC: The Aspen Institute. Available from: https://files.eric.ed.gov/fulltext/ED523244.pdf

47. Organization for Economic Co-operation and Development. Tackling high inequities: creating opportunities for all. Social Policy Division of the OECD Directorate for Employment, Labour and Social Affairs. June 2014. Available from: https://www.oecd.org/unitedstates/Tackling-high-inequalities.pdf

48. Health Inequalities Unit - Department of Health UK. Equity Action: Tools - To improve the health equity focus in cross-government policy making. Available from: http://www.healthinequalities.eu/projects/past-projects/equity-action/

49. Splansky-Juster J. New research study: when collective impact has an impact. March 1, 2018. Collective Impact Forum. Available from: http://collectiveimpactforum.org/blogs/700/newresearch-study-when-collective-impact-has-impact 
50. Collective Impact Forum. What is collective impact? Available from: http://collectiveimpactforum.org/what-collective-impact

51. Solar O, Irwin A. A conceptual framework for action on the social determinants of health. Social Determinants of Health Discussion. Paper 2 (Policy and Practice). 2010. http://www.who.int/sdhconference/resources/ConceptualframeworkforactiononSDH_eng.pd $\mathrm{f}$

52. About the Alabama Black Belt Heritage Area. The Official Website of the Alabama Black Belt Heritage Area. Available from: http://alblackbeltheritage.org/about-alabama-black-beltheritage-area

53. The Black Belt Community Foundation Vision. A Transformed Black Belt. http://blackbeltfound.org/about-us/our-vision/

54. United States Census Bureau. Official Poverty Measure. Macon County, AL. Available from: https://data.census.gov/cedsci/results/all?q=Official\%20Poverty\%20Measure\&t=Official\%2 0Poverty\%20Measure\&g=0100000US\&ps=search*suggestions@false

55. Settles C. How to create a tele-healthcare hub, School, Health \& Libraries Broadband Coalition (SHLB): Promoting Broadband for Anchor Institutions and their Communities. Posted January 10, 2018. Available from: https://shlb.siteym.com/blogpost/1628552/292608/How-to-Create-a-Tele-Healthcare-Hub

56. The University of Alabama Institute for Communication and Information Research and the Black Belt Community Foundation. (Various studies.) Available from: https://cchs.ua.edu/college-works-with-rural-communities-to-reduce-obesity/. https://cchs.ua.edu/research-roundup-an-intervention-program-for-childhood-obesity/. https://cchs.ua.edu/researchers-receive-800000-grant-for-community-based-participatoryresearch/. https://cchs.ua.edu/people/cynthia-moore/. https://cchs.ua.edu/pickens-countyhealth-scholars-welcomed/. 